\title{
Does "Liking" Lead to Loving? The Impact of Joining a Brand's Social Network on Marketing Outcomes
}

\section{Citation}

John, Leslie K., Oliver Emrich, Sunil Gupta, and Michael I. Norton. "Does 'Liking' Lead to Loving? The Impact of Joining a Brand's Social Network on Marketing Outcomes." Journal of Marketing Research (JMR) 54, no. 1 (February 2017): 144-155.

\section{Published Version}

http://dx.doi.org/10.1509/jmr.14.0237

\section{Permanent link}

http://nrs.harvard.edu/urn-3:HUL.InstRepos:32062564

\section{Terms of Use}

This article was downloaded from Harvard University's DASH repository, and is made available under the terms and conditions applicable to Open Access Policy Articles, as set forth at http:// nrs.harvard.edu/urn-3:HUL.InstRepos:dash.current.terms-of-use\#OAP

\section{Share Your Story}

The Harvard community has made this article openly available.

Please share how this access benefits you. Submit a story.

\section{Accessibility}




\section{Does “Liking” Lead to Loving?}

The Impact of Joining a Brand's Social Network on Marketing Outcomes

Forthcoming, Journal of Marketing Research

Leslie K. John, Assistant Professor of Business Administration, Harvard Business School email: ljohn@hbs.edu

Oliver Emrich, Professor of Marketing, Johannes Gutenberg University Mainz email: oemrich@uni-mainz.de

Sunil Gupta, Professor of Business Administration, Harvard Business School email: sgupta@hbs.edu

Michael I. Norton Professor of Business Administration, Harvard Business School email: mnorton@hbs.edu

Acknowledgements:

The authors are grateful for Evan Robinson's ingenious programming skills and for Marina Burke's help with data collection. The authors thank the review team for constructive feedback throughout the review process. 


\begin{abstract}
Does “liking” a brand on Facebook cause a person to view it more favorably? Or is "liking” simply a symptom of being fond of a brand? We disentangle these possibilities and find evidence for the latter: brand attitudes and purchasing are predicted by consumers’ preexisting fondness for brands, and are the same regardless of when and whether consumers "like” brands. In addition, we explore possible second-order effects, examining whether "liking” brands might cause consumers' friends to view that brand more favorably. When consumers see that a friend has "liked” a brand, they are less likely to buy the brand relative to a more meaningful social endorsement: learning that a friend likes a brand, in the offline sense. Taken together, five experiments and two meta-analyses $(\mathrm{N}>14,000)$ suggest that turning "liking” into improved brand attitudes and increased purchasing by either consumers or their friends may require more than just the click of a button.
\end{abstract}

Keywords: field experiments; social media; marketing measurement and effectiveness; brand evaluation; peer influence 
What happens when a consumer joins a brand's online social network (SN)? For example, on Facebook (FB), the dominant social networking platform, what happens when a consumer clicks the "like” button for a brand, causing her to join that brand's FB page? And, what happens to her friends' behavior when they see that she has clicked that "like” button? Given that "liking” a brand causes consumers to become part of that brand's online SN, one might expect "liking" to cause positive changes in consumer behavior, from buying more of that brand's offerings to spreading positive word of mouth. At the same time, people who "like" a brand on FB may simply be expressing their existing preference for that brand - one that is also likely to be held by their friends - such that publicly joining that brand's network through one small click of a mouse or press of a finger is unlikely to change their subsequent behavior. Given the indiscriminate manner with which consumers "like" brands - with many FB users "liking" hundreds of brands, musicians, and television shows - expecting "liking" to change attitudes and behavior may be unrealistic. In this article, we assess the first- and second-order effects of joining a brand's SN on marketing outcomes. Note that we do not assess the potential usage of brand SNs as relationship-building tools. Future research should examine uses of brand SNs as targeting and communication tools; by enabling consumers to self-identify as fans of a brand, brand SNs could serve as a means to build and engage with a receptive audience.

Although firms now have several third-party social networking sites from which to choose, including Google+ and China's RenRen, we constrain our analysis to the dominant global platform: FB. Specifically, in both field and lab experiments, across both attitudinal and behavioral outcomes, and across short and longer time spans, we find that "liking" a brand has no positive direct effect on consumer attitudes or purchases; if anything, its effect is detrimental. Second, inducing consumers to "like" a brand is less effective at inducing their friends to try the 
brand relative to more meaningful endorsements that are external to FB - such as a friend expressing liking in a face-to-face interaction.

\section{Marketing and Social Media}

Marketers spend billions of dollars each year on social media to establish and maintain a presence on online social networking sites (Moorman 2015). Eighty percent of Fortune 500 companies are on FB, with many having well over one million fans (Barnes, Lescault, and Wright 2013; Shively 2014). As one executive proclaimed: "Facebook should be a key part of the marketing mix for most consumer brands” (Vranica and Raice 2012).

Even as marketers are investing heavily in this medium, they are increasingly asking: “What are we getting for our dollars?” (Michael Sprague, VP Marketing, KIA, from Vranica and Raice 2012). As one CEO noted, recent years have seen "hype and a competitive race to acquire the most FB Fan connections, but brand marketers are sobering up and beginning to ask hard questions around the ROI of social marketing. Perhaps no question is asked more than 'What is the value of a Facebook brand fan?'” (Syncapse 2013). Consistent with these claims, a recent survey of Chief Marketing Officers indicated that 87\% of those investing in social media have not yet been able to document its impact (Moorman 2015). In sum, marketers have become dissatisfied with the currently available metrics for evaluating their social media investments (eMarketer 2012). We address this knowledge gap by assessing whether joining a brand’s social network site changes consumer behavior - either of the consumers who join (i.e., first-order effects) or of the friends of those consumers (i.e., second-order effects).

\section{Documenting and Explaining Outcomes Associated with Social Network Membership}

First-order associations. Members of Starbucks’ FB page (i.e., “Fans”) spend more and transact more frequently relative to non-members (Lipsman et al. 2012). It is possible that 
joining the brand's SN causes people to buy more, with a causal association taking one of two forms: a pure treatment effect or a treatment-by-selection effect. A pure treatment effect would suggest that SN membership induces change in a consumer. For example, joining Starbucks’ SN would cause a consumer to spend more at Starbucks than he ordinarily would have. In a treatment-by-selection effect, the effect of the SN on behavior would be restricted to the subset of consumers with a predisposition toward joining the network. For example, joining the brand's SN would cause loyal Starbucks customers to spend more relative to loyal customers who did not join; joining the brand's SN would have no impact on the behavior of non-loyal customers. Finally, of course, the association between joining a network and spending may have no causal element: it could simply be a selection effect such that consumers who frequent Starbucks are more likely to join the brand's SN than those who do not frequent Starbucks. In other words, spending money at Starbucks could be a cause, rather than consequence, of brand SN membership.

To disentangle selection effects from causal effects, a counterfactual is needed: how much would a consumer have spent at Starbucks had he not joined the brand's SN? Recent research has made significant progress in statistically inferring this counterfactual (Manchanda, Packard, and Pattabhiramaiah 2015): Customers were invited to join a firm’s new online community, and purchasing behavior before and after launch was compared between those who joined versus did not join. Based on a difference-in-differences analysis, approximately 19\% of the post-launch revenue was attributed to a causal effect of the brand community. However, the difference-in-difference approach cannot differentiate pure treatment effects (brand community membership causes people to buy) from treatment-by-selection effects (community membership drives buying for those predisposed to joining) (Greene 2012; Lechner 2011). In either case, 
however, as Manchanda et al. (2015) conclude, the observed effect is unlikely to be driven purely by selection.

Building on previous research, our experiments enable us to pinpoint which of these three possible effects - pure treatment, treatment-by-selection, or pure selection - might account for positive associations between brand SN membership and marketing outcomes. Experiment 1 is designed to detect pure treatment effects; participants are randomized to "like" - or to not "like" - a brand on FB. Given that this experiment (and 15 others reported in the Web Appendix) found no evidence of pure treatment effects, Experiments 2A-C test whether positive associations between brand SN membership and marketing outcomes are driven by treatment-by-selection effects or merely by selection effects. To do so, we developed an experimental approach - intentto-“like” - in which participants are first asked whether they are interested in "liking” a brand. Half of those responding affirmatively are then randomly assigned to join the brand's SN (i.e., to "like” it on FB). We test for selection effects (do outcomes differ between those willing versus unwilling to "like” a brand?) and treatment-by-selection effects: among those willing to "like,” are marketing outcomes improved for those randomized to join the SN compared to those randomized not to join?

We suggest that unlike purchasing a product or even watching an advertisement - which “cost” money and time, respectively - clicking a "like” button may be insufficiently costly to alter subsequent behavior. Consistent with this perspective, Manchanda et al. (2015) showed that the positive effect of brand SNs was driven by those who post content, with no increased purchasing among “lurkers” - those who joined the community but did not post content. Moreover, Kristofferson, White and Pelozo (2014) show that making a public but token commitment to a charitable initiative if anything decreased people’s subsequent propensity to 
provide meaningful support to that cause. We suspect these effects hold with for-profit initiatives as well; indeed, a recent descriptive study conducted by Australia's Ehrenberg-Bass Institute of Marketing Science found that only $0.45 \%$ of consumers who joined FB networks (of major consumer brands including Coca Cola and Procter \& Gamble) subsequently “engaged” with that network (e.g., through tags, additional likes, shares, comments, etc.; Creamer 2012), again suggesting that "likes” may not influence subsequent behavior. We build on Kristofferson et al. (2014) by employing an approach that, as described above, allows us to simultaneously assess the independent effects of selecting into brand SNs (actually joining by clicking "like”) and merely liking (being fond of) that brand. In sum, because joining a brand's FB network is a token act, we predicted that joining (by "liking” the brand) would be unlikely to improve brand attitudes or increase buying behavior. Instead, we expected that first-order associations would be driven purely by selection (simply liking the brand).

Documenting and accounting for first-order effects of brand SN membership on marketing outcomes is also of practical importance because these effects should inform resource allocation. For example, if positive associations arise purely due to treatment effects, increased investment in brand SN infrastructure is warranted; if they arise purely due to selection effects, marketers may wish to focus fewer resources in this specific channel; if they arise due to treatment-by-selection effects, marketers may wish to pursue a hybrid strategy. Moreover, we investigate the value of social media within the context of other marketing activities. Specifically, we compare the outcomes associated with brand SNs - regardless of whether they are driven by selection, treatment, or treatment-by-selection - to outcomes associated with other marketing expenditures such as advertising. Our results therefore provide practical insights for marketers on the optimal allocation of marketing resources. 
Second-order associations. Friends of consumers signaling endorsement through purchasing a given product are more likely to buy that product relative to those not connected (e.g., Oestreicher-Singer and Zalmanson 2010). We explore whether such second-order associations influence friends' behavior when the endorsement is much weaker: evidence that a friend has merely joined the brand's online SN. Specifically, we assess whether a target consumer "liking" a brand on FB predicts the attitudes and behaviors of that target's FB friends toward that brand - and if so, what explains the association.

As with first-order effects of brand SNs on marketing outcomes, this second-order association could be causal: “liking” a brand could cause a person’s FB friends to purchase. On the other hand, the association could simply be a byproduct of selection via homophily (McPherson, Smith-Lovin, and Cook 2001): since friends have similar tastes, recipients of social endorsements may have purchased in the absence of such endorsements. We disentangle these possibilities in a field experiment in which people are randomized to receive - or to not receive a message indicating that their friend has "liked" a given brand. Thus, as with first-order associations, our experimental paradigm provides the counterfactual of whether a consumer would have bought a product had he not viewed a social endorsement.

We predicted a causal effect of social endorsement on marketing outcomes, consistent with previous research (Aral and Walker 2011; Bapna and Umyarov 2014). However, we expected that the nature of the social endorsement matters: we assess whether a token social endorsement (evidence that Mark "likes" Coca Cola on FB) is less effective than a more meaningful social endorsement (evidence that Mark actually likes Coca Cola). Consistent with Kristofferson et al. (2014), we predicted that FB "likes” would be interpreted as token endorsements and therefore be less effective compared to more meaningful endorsements. 
As with first-order associations, documenting and accounting for second-order associations is also of practical importance to marketers. If homophily drives the positive effect of social endorsement, sophisticated segmentation techniques (i.e., targeting groups of people for whom one's offerings are most enticing) will be useful. If on the other hand, social endorsement on SNs causes purchasing, it would behoove marketers to identify influential people and induce them to "like" their brands on FB in order to create more positive associations among those consumers’ friends (e.g., Aral and Walker 2012).

\section{Analytical Approach}

Because we predicted that joining a brand's SN is unlikely to change consumers’ attitudes and behavior - that there are neither first-order treatment nor treatment-by-selection effects of "liking" - we took seven steps to bolster the validity of any observed null effects. First, in the design phase, we planned to use very large sample sizes. Second, in Experiment 2C, we included a within-subjects component to further enhance our power to detect possible positive effects of "liking." Third, we conducted experiments with factorial designs in which we crossed our "liking” manipulations with the provision of advertising, testing for nuanced effects (Experiments 2B \& C): detecting effects due to advertising should bolster the credibility of null effects of "liking," since such results would suggest that the experimental paradigm is capable of producing effects. Fourth, in administering the experiments, we collected many supplementary outcome measures that "liking" might affect in addition to the primary outcome measure (which was specified a priori for each experiment), increasing the likelihood of detecting a significant positive result. Due to space constraints, we report only the primary outcome measure here; all measures and results are reported in the Web Appendix. Survey attrition rates are also reported in the Web Appendix (generally, they were low and equivalent across conditions). Fifth, in the 
analysis phase, in addition to conducting conventional null hypothesis testing, we report the Bayes factor in each experiment. Bayes factors provide a probabilistic assessment of whether the null hypothesis - that FB liking has no impact - is more likely to be true than the alternative hypothesis (Kass and Raftery 1995). Sixth, we conducted supplementary analyses in which we controlled for various individual differences that might moderate the effect of the liking manipulation, including whether participants had liked brands on FB and their number of FB contacts. These supplementary analyses are consistent with the primary results. Seventh, we conducted two meta-analyses: in the first (reported after Experiment 1), we pooled all data from the total of 16 experiments we have run which test for pure treatment effects of "liking"; in the second, we pooled all data from the total of five experiments we have run which test for treatment-by-selection effects of "liking” (reported after Experiment 2C). We base all analyses on pre-specified sample sizes and we report all data exclusions, manipulations, and measures. Overview of Experiments

Experiments 1 and 2A-C focus on first-order effects; these experiments document and explain positive associations between SN membership and marketing outcomes. Experiment 1 investigates whether such associations arise purely due to treatment effects by testing whether inducing consumers to join brand SNs causes changes in their brand attitudes and purchasing propensity. Given that we find no evidence of pure treatment effects, in Experiments 2A-C, we test for treatment-by-selection effects and selection effects, using the intent-to-“like” paradigm described above. Finally, Experiment 3 focuses on second-order effects, testing whether joining a brand SN causally influences the joiner’s friends' attitudes and behaviors toward that brand. 
Experiment 1 tests for pure treatment effects: Does inducing consumers to join a brand's SN affect their attitudes and behavior toward that brand? We manipulated whether participants were induced to join a brand’s FB network (by “liking” it) or to merely indicate whether they liked the brand without joining its FB network. In the induction, participants were asked to click on a "like" button for a brand; upon doing so, they became a member of the brand's FB page. In the ideal test, the induction would be $100 \%$ effective, whereby all participants receiving the induction treatment comply, by joining the brand's SN. Complete or even near-complete compliance is unlikely, which is problematic because it increases the chance that the predicted null result is an artifact of an ineffective "liking” induction. To address this issue, we manipulated the incentive to "like" the brand. If the incentive successfully induces different compliance rates, we would expect (improved) marketing outcomes to track with the incentive manipulation - if there is a pure treatment effect. The experiment was therefore a six condition between-subjects design in which participants were randomized to either one of two control conditions (described below) or to one of four experimental conditions differing in compliance incentive to "like” (no incentive, tiny: \$0.01, small: \$0.05, or large: \$0.50).

\section{Procedure}

Participants $\left(\mathrm{N}=767 ; 54.0 \%\right.$ male; $\mathrm{M}_{\mathrm{age}}=33.2$ years, $\left.\mathrm{SD}=10.8\right)$ who indicated that they had a FB account were recruited from Amazon’s Mturk. In this and all experiments in this paper, the experiment began with the following procedure: First, all participants were asked to log into their FB accounts and answered two questions that required them to be logged in to give correct answers. Participants also completed a variety of questions about their FB usage. All measures and stimuli are included in the Web Appendix. 
Participants were randomized to either an inert control in which we simply administered the dependent measures, a check box control in which participants privately checked a box indicating whether or not they liked Coca Cola, or one of four conditions in which they were asked to "like" Coca Cola.

Participants in the experimental "liking” conditions were given the opportunity to join the brand's SN by clicking on a “like” button (Figure 1). Participants were told: “please click on the 'like’ button below for the brand: Coca Cola.” This button operated just as those regularly encountered on the Internet: upon clicking it, the participant became a member of the brand's FB network, and this information was posted on the participant's FB profile. Critically, in this and all experiments, we covertly recorded whether each participant complied - by clicking the "like" button. Doing so enabled us to measure the proportion of participants that complied (i.e., joined the brand SN) and hence, the effectiveness of the "liking” induction.

Participants assigned to "like” the brand were further randomized to receive either no incentive to comply or an incentive that was either tiny (\$0.01), small (\$0.05), or large (\$0.50). In these conditions, the following wording accompanied the "like” button: "NOTE: you will receive a bonus payment of $\$ 0.01$ [\$0.05] [\$0.50] if you click on the like button. (If you click on the like button, this bonus payment will be applied to your payment on Mturk).”

Participants randomized to the check box control condition were presented with a check box labeled "like" under the logo for the target brand and asked "Please check the box below to indicate if you like the brand: Coca Cola” (Figure 1). Thus, the wording in the control condition was semantically equivalent to the experimental condition; the key difference was that participants did not join the SN after checking “like.” In other experiments, we used textually identical wording across conditions and obtained similar results (see the Web Appendix). 
We assessed brand favorability immediately following the "liking” induction on a 7-point response scale ( 1 = very unfavorable -7 = very favorable). To minimize demand effects, participants rated seven brands in addition to the target brand (Coca Cola).

Results and Discussion

Compliance. The different incentives were successful in altering compliance rates (check box control $=57.8 \%$, no incentive $=38.8 \%$, tiny $=44.9 \%$, small $=58.6 \%$, high $=61.4 \% ; \chi^{2}(4)=$ 20.10, $p<.0005)$.

Brand favorability. Despite this increase in share of participants "liking” the brand, there were no significant differences between conditions in brand favorability $\left(\mathrm{M}_{\text {inert_control }}=4.81\right.$, SD $=1.59, \mathrm{M}_{\text {checkbox_control }}=4.75, \mathrm{SD}=1.88 ; \mathrm{M}_{\text {no_incentive }}=4.75, \mathrm{SD}=1.89, \mathrm{M}_{\text {tiny }}=5.01, \mathrm{SD}=$ $\left.1.61 ; \mathrm{M}_{\text {small }}=4.98, \mathrm{SD}=1.75 ; \mathrm{M}_{\text {large }}=5.12, \mathrm{SD}=1.72 ; \mathrm{F}(5,656)=.86, p=.51\right)$.

Bayes factors. $\mathrm{HO}$ - that there is no effect across conditions - is at least 10 times more likely than H1, which constitutes strong evidence for the null.

In sum, despite succeeding at inducing different compliance rates, Experiment 1 found no evidence of a treatment effect of "liking."

\section{META-ANALYSIS 1}

Although the "liking” induction in Experiment 1 did not produce full compliance, there was no movement in any of the outcome measures as a function of experimentally-induced differences in compliance, suggesting a true null result rather than a false negative. Nonetheless, we conducted 15 additional experiments using a methodology similar to Experiment 1 inducing participants to "like" or to not "like" a brand - to further attempt to detect a pure treatment effect (see the Web Appendix). If there truly is a treatment effect, the increased power afforded by pooling the data $(\mathrm{N}>6000)$ should facilitate its detection in the face of incomplete 
compliance. These experiments also tested possible moderators. For example, we manipulated whether the outcome measures were administered immediately after "liking” or after some delay, to test whether a treatment effect might only emerge after consumers have had time to experience and be influenced by the SN. Similarly, in another experiment, we manipulated the novelty of the brand, in case a treatment effect might only emerge for newer brands. The metaanalysis assessed whether the effect of the "liking” induction on the primary (i.e., first administered) outcome measure was significant. Results indicated that "liking” a brand on FB had a marginally significantly negative impact (mean effect size: $\mathrm{d}=-.051, p=.06$ ). Based on these experiments which test for possible first-order treatment effects, the causal effect of "liking” is certainly not positive, and if one exists, our best estimate is that it is negative.

\section{EXPERIMENT 2A}

The results of Experiment 1 and a meta-analysis suggest that brand SNs do not positively affect consumers' attitudes or behaviors - whether immediately or after a delay, or for new or established brands - due to a pure treatment effect. Therefore in Experiments 2A-C, we test whether associations between brand SN membership and marketing outcomes are driven by treatment-by-selection effects versus pure selection. We assess whether brand SNs have an impact on certain types of individuals - those who may have a predilection toward the brand (i.e., treatment-by-selection) - or whether brand SN membership is merely a "symptom” of being fond of a brand (i.e., selection). We distinguish these two possibilities using an intent-to-“like” procedure whereby we first ask participants whether they are willing to "like" a given brand; critically, only some of these "opt-inners” are subsequently asked to actually "like” the brand. In Experiment 2A opt-inners for the target brand (Pepsi) were randomized to one of three conditions: an experimental condition, in which they were presented with a "like" button, or one 
of two control conditions in which they completed the dependent measures without having "liked" the brand, despite their stated willingness to do so. Specifically, in the holdout control condition, participants simply completed the measures, while in the jilted control condition, participants actually clicked "like" but received an error message telling them they could not join. These control conditions allow us to assess how opt-inners would have viewed Pepsi had they not joined its FB page. Hence, the design enables us to distinguish selection effects of "liking” - Pepsi fans are more likely to "like” it than non-Pepsi aficionados - from treatment-byselection effects - attitudes toward the brand improve when Pepsi fans join brand SNs relative to when Pepsi fans do not join.

Taking into account the opt-in variable - through which participants indicated whether they were willing to "like" Pepsi, unwilling to "like" it, or had already "liked" it - and the randomization variable, through which those who were willing to "like” Pepsi (the opt-inners) were randomized to one of three conditions (experimental, holdout control, and jilted control), the experiment was a five condition between-subjects design.

\section{Procedure}

Participants $\left(\mathrm{N}=1343 ; 55.1 \%\right.$ male; $\mathrm{M}_{\mathrm{age}}=32.1$ years, $\mathrm{SD}=10.5 ;$ NS between randomized conditions), indicated whether they wanted to click on the "like" button for Pepsi by endorsing either: "Yes, I want to click on the "Like” button for Pepsi," "No, I do not want to click on the "Like" button for Pepsi," or "Not applicable, I am already a member of the Pepsi Facebook page.” They were told that if they answered affirmatively, a Pepsi "like” button would appear at some point during the experiment, and they would be expected to click it.

Opt-inners (i.e., those who said "Yes, I want to click on the "Like" button for Pepsi") were randomized to one of three conditions: experimental, jilted control, or holdout control. In 
the experimental condition, the "like" button appeared on the page immediately following the self-sorting item. In the jilted control condition, the "like" button also appeared on the page immediately following the self-sorting item; however, after having pressed the button, an error message was displayed: "This link is malfunctioning due to an internal service error on the [site name] survey site. Please click OK then return to the survey and click the NEXT button to continue." In the holdout control condition, the "like" button appeared at the end of the survey after the dependent measures had been administered.

We measured brand favorability as in Experiment 1.

Results and Discussion

Self-sorting. The distribution of responses to the self-sorting item was: opt-out: $72.3 \%$ (n = 876), opt-in: 19.4\% $(\mathrm{n}=235)$, already liked: 8.3\% $(\mathrm{n}=101)$.

Compliance. Participants in the experimental and holdout control conditions were presented with a (functional) "like" button. The majority of these participants (83.4\%) clicked it (NS between conditions $\left.\chi^{2}(1)=.16, p=.69\right)$.

Brand favorability. There were significant differences in brand favorability $(F(4,1204)=$ 62.33, $p<.0005$; Figure 2). Specifically, favorability was similar among participants in the conditions consisting of participants with a predilection toward the brand (i.e., already "liked," and the three opt-in groups: experimental, jilted control, holdout control; $\mathrm{t}(333)=.07, p=.94)$. Brand favorability was significantly higher in these four conditions relative to the opt-out condition $\left(\mathrm{M}_{\text {opt-in+already_liked }}=5.55, \mathrm{SD}=1.38 ; \mathrm{M}_{\text {opt-out }}=3.93, \mathrm{SD}=1.67 ; \mathrm{t}(1207)=15.75, p<\right.$ .0005). These results suggest that "liking" had no effect over simply being fond of the brand to begin with. 
Bayes factors. In Experiments 2A-C, we test the strength of the null hypothesis that there is no treatment-by-selection effect: that brand attitudes are equivalent between opt-in experimental and opt-in control conditions. In Experiment 2A, H0 is 3.65 times more likely than $\mathrm{H} 1$, offering substantial evidence for the null.

Experiment 2A suggests that the positive marketing outcomes associated with brand SN membership are not the result of treatment-by-selection effects: there were no differences in brand favorability between the experimental and either the holdout or jilted control conditions. Instead, Experiment 2A suggests that these associations are driven by selection: people who were willing to "like" the brand - regardless of whether they actually did so - had more favorable attitudes toward the target brand.

\section{EXPERIMENT 2B}

Experiment 2A suggests that the positive marketing outcomes associated with brand SN membership are driven by selection. However, it is possible that a treatment-by-selection effect might emerge when brand SN membership is coupled with traditional marketing activities - such as advertisements. For example, a positive effect of "liking” may require on-brand messaging to be realized. Experiment 2B tests this possibility by randomizing not only whether opt-inners join the brand SN as in Experiment 2A, but also whether they encounter advertising for the brand. Using the same intent-to-“like” methodology as Experiment 2A, Experiment 2B was a 4 (optout, already “liked,” opt-in experimental, and opt-in holdout control) x 2 (advertising or no advertising) between-subjects design. (We did not include a jilted control condition since it produced results equivalent to the holdout control in Experiment 2A.)

\section{Procedure}


Participants $\left(\mathrm{N}=940 ; 45.6 \%\right.$ male; $\mathrm{M}_{\mathrm{age}}=35.6$ years, $\mathrm{SD}=11.3 ;$ NS between randomized conditions) indicated whether they wanted to click on the "like" button for the target brand (Coca Cola) using the same procedure are Experiment 2A. Opt-inners were randomized to either the experimental condition, in which they were presented with a "Like" button to press immediately after having opted in, or a control condition, in which the "Like” button appeared following the dependent measures.

Next, participants were asked to view three 1 minute clips about Greenland. For half of participants, a unique 30 second Coca Cola advertisement preceded each clip. These participants were told: "before each video about Greenland, you will be shown a 30-second advertisement from our sponsor, Coca Cola.” Participants could not advance until the videos had finished playing, and we included three quiz questions at the end to measure whether participants had paid attention to the videos (71\% answered all three questions correctly, NS between conditions).

We measured brand favorability for Coca Cola on the same scale as the previous experiments.

Results and Discussion

Self-sorting. The distribution of responses to the self-sorting item was: opt-out: $59.9 \%$ (n = 459); opt-in: 30.9\% $(\mathrm{n}=237)$; already-liked: $9.1 \%(\mathrm{n}=70)$.

Compliance. Participants in the experimental and control conditions were presented with a "like" button. Unlike in Experiment 2A, we observed differential compliance (experimental= $84.7 \%$, control $\left.=68.1 \% ; \chi^{2}(1)=9.13, p=.003\right)$; importantly however, most $(84.7 \%$ of $)$ participants in the experimental condition - in which the dependent measure was administered after "liking” - complied. 
Brand favorability. A 4x2 ANOVA revealed a main effect of advertising $\left(\mathrm{M}_{\text {No_advertising }}=\right.$ 4.37, $\left.\mathrm{SD}=1.80 ; \mathrm{M}_{\text {advertising }}=5.11, \mathrm{SD}=1.67 ; \mathrm{F}(1,717)=14.64, p<.0005\right)$, a main effect of self-sorting $(\mathrm{F}(3,717)=49.83, p<.0005)$, and no interaction $(\mathrm{F}(3,717)=1.01, p=.39$; Figure

3). Replicating Experiment 2A, follow-up tests revealed that brand favorability was significantly higher among those willing to "like” the brand - regardless of whether they had actually done so - relative to those unwilling to do so $\left(\mathrm{M}_{\mathrm{opt}-\text { in+already_"liked" }}=5.62, \mathrm{SD}=1.42 ; \mathrm{M}_{\text {opt-out }}=4.15, \mathrm{SD}=\right.$ 1.75; $\mathrm{t}(723)=11.94, p<.0005)$. Interestingly, comparing the favorability ratings across the randomized, opt-in conditions reveals that joining the brand's SN decreased brand favorability $\left(\mathrm{M}_{\text {opt-in_control }}=5.87, \mathrm{SD}=1.22 ; \mathrm{M}_{\text {opt-in_experimental }}=5.39, \mathrm{SD}=1.60 ; \mathrm{t}(221)=2.51, p=.01\right), \mathrm{a}$ result consistent with the meta-analysis reported earlier.

Bayes factors. When no advertisements were delivered, $\mathrm{H} 0$ - that there is no treatmentby-selection effect - was 3.32 times more likely than H1. Interestingly, when ads were shown, H1 was 3.34 times more likely than H0, indicating support for the alternative hypothesis that “liking,” when combined with ads, decreases brand favorability.

Consistent with Experiment 2A, brand favorability was higher among those willing to join a brand $\mathrm{SN}$ - irrespective of actually joining - relative to those unwilling to do so, providing evidence of a pure selection effect. Importantly, we observed a significant positive impact of advertising, suggesting that our participants are willing to change their attitudes - but only in response to advertising, and not "liking." Experiment 2B extends the results of Experiment 2A, showing that at least in the short run, joining a brand's SN does not change attitudes even when combined with advertising - despite the fact that the advertising was effective. 
Experiments 2A and B suggest that the positive association between brand SN membership and attitudes toward that brand is driven by selection: attitudes toward the brand are the same among people who are fond of a brand - regardless of whether they officially "like" it on FB. However, it could be argued that positive treatment-by-selection effects take time to emerge, surfacing only after members have had time to experience the network. In other words, brand SNs may further boost a consumer's view of that brand via increased contact over time. Moreover, such positive treatment-by-selection effects might be facilitated by advertising. Experiment 2C tests these possibilities longitudinally, and also assesses buying behavior.

Experiment 2C used the same intent-to-“like” methodology as Experiments 2A and B, and we assessed brand favorability immediately after the intent-to-“like” treatment (Time 1), as well as a week later (Time 2). In addition to providing an additional test for the emergence of treatment-by-selection effects, the longitudinal feature of this experiment also increases power: participants' brand favorability ratings were obtained both immediately after the induction and over time. As described below, we also included a behavioral measure: participants were given a coupon for the target brand; we compared redemption rate across conditions. Experiment 2C also included a messaging treatment: half of participants were sent an advertising message for the brand mid-way through the longitudinal experiment. In sum, Experiment 2C was a 4 (opt-out, already “liked,” opt-in experimental, opt-in control; between-subjects) x 2 (advertising, no advertising; between-subjects) x 2 (Time 1, Time 2; within-subjects) mixed design.

Time 1 Procedure 
Participants $(\mathrm{N}=4841)$ completed the self-sorting item as in Experiments 2A and 2B for the brand: Burt's Bees. ${ }^{1}$ The distribution of responses to the self-sorting item was: opt-out: 27.8\% ( $\mathrm{n}=1303)$; opt-in: 66.5\% ( $\mathrm{n}=3118)$; already “liked”: 5.7\% $(\mathrm{n}=265)$.

Next, some randomly selected participants who had indicated that they were either unwilling to "like" the brand or that they had already "liked" it were screened out. We oversampled opt-inners because they would be further randomized to one of two conditions (experimental versus control). Based on Experiments 1-2B we concluded that if there is a treatment-by-selection effect, it is likely to be smaller than that of selection, meaning that we would need a larger sample size to be sufficiently powered to detect differences between the experimental and control conditions - the critical test of treatment-by-selection effects. Those screened out were simply told that they did not meet the eligibility criteria and were thanked for their interest. The screen-out procedure resulted in a sample size of $3669\left(\mathrm{n}_{\text {opt-out }}=453, \mathrm{n}_{\text {opt-in }}=\right.$ 3118, $\mathrm{n}_{\text {already “"iked” }}=98$ ).

The intent-to-"like" manipulation was the same as that used in Experiment 2B: opt-inners were randomized to either the experimental condition in which they were presented with a "like" button immediately after having opted in, or to the control condition in which the "like" button was presented after all dependent measures had been administered (i.e., at the end of the Time 2 survey).

We assessed brand favorability for Burt's Bees using the same scale as the previous experiments, then offered participants the opportunity to buy a tube of Burt's Bees lip balm. Participants were offered a bonus payment of $\$ 0.20$ which they could either accept as cash or use to buy the lip balm (for the discounted price of $\$ 0.20$; the approximate retail price of a tube of

\footnotetext{
${ }^{1}$ We chose Burt's Bees because out of seven possible brands, pre-test participants ( $\mathrm{N}=50$ ) were most willing to buy it ( $\mathrm{M}=4.1$ on a 7-point scale, $\mathrm{SD}=2.0$ ) and join its Facebook page (percent willing to "like" $=40 \%$ ).
} 
Burt’s Bees lip balm was $\$ 3.30$ as of December 2014). ${ }^{2}$ Participants then indicated (yes or no) whether they wanted to buy the lip balm.

Advertising Treatment between Time 1 and 2

Mid-week - approximately 3 days after the Time 1 survey and 3 days before the Time 2 survey) - all participants who had completed the Time 1 survey were sent an email thanking them for their participation and reminding them that an invitation to the Time 2 survey was coming soon. Those who had not opted to buy a tube of Burt's Bees lip balm at the end of the Time 1 survey were given another opportunity to do so by clicking on a link in the email. We were unsuccessful at contacting $0.8 \%$ of the Time 1 completers (27/339) because their email addresses were invalid.

For half of participants, this email also included an advertising message for Burt's Bees from the brand’s website (December 2014): “Classic Beeswax Lip Balm keeps lips warm and cozy when the weather outside is cold and dreary. It's the little lip balm that could. Which is probably why for the past 30 years it’s been loved by people all over the world.”

Time 2

Participants who had completed the Time 1 survey and for whom we had a valid email address ( $\mathrm{N}=3391)$ were sent an email instructing them to click on a link to the Time 2 survey. The response rate was $76 \%\left(\mathrm{~N}=2582 ; 40.0 \%\right.$ male; $\mathrm{M}_{\text {age }}=34.43$ years, $\mathrm{SD}=11.16 ; N S$ between randomized conditions). The brand favorability measure was administered, followed by the "like" button for participants randomized to the holdout control condition. Two final items assessed whether participants had received and read the mid-week email.

\footnotetext{
${ }^{2}$ After having pre-tested several pricing schemes, we settled on the $\$ 0.20$ bonus / voucher price because it produced neither floor nor ceiling effects on redemption.
} 
Results and Discussion

Compliance. Participants in the opt-in conditions were presented with a "like" button. Compliance was marginally significantly different between these conditions (opt-in experimental $=84.7 \%$, opt-in control $\left.=81.8 \% ; \chi^{2}(1)=3.73, p=.054\right)$; importantly however, at 83.4\%, compliance was high overall.

Brand favorability at Time 1. The first administration of this measure enabled us to assess any immediate positive effects of joining a brand's FB page. A one-way ANOVA revealed significant differences as a function of "liking" status $(\mathrm{F}(3,3395)=80.05, p<.0005$; Figure 4$)$. Follow-up pairwise comparisons revealed that relative to those unwilling to "like" the brand, favorability was significantly higher among those in the opt-in control condition $\left(\mathrm{M}_{\mathrm{opt}-\mathrm{out}}=4.84\right.$, $\left.\mathrm{SD}=1.31 ; \mathrm{M}_{\text {opt-in_control }}=5.81, \mathrm{SD}=1.09 ; \mathrm{t}(1831)=14.54, p<.0005\right)$, the opt-in experimental condition $\left(\mathrm{M}_{\text {opt-in_experimental }}=5.81, \mathrm{SD}=1.11 ; \mathrm{t}(1832)=14.28, p<.0005\right)$, and those who had already "liked" the brand $\left(\mathrm{M}_{\text {already “"liked" }}=5.86, \mathrm{SD}=1.05 ; \mathrm{t}(438)=6.73, p<.0005\right)$. As in Experiments 2A and 2B, the latter three conditions, which consist of individuals who are willing to "like" the brand but differ exogenously in whether they did so, did not differ $(F(2,3042)=$ $.09, p=.92)$. At least in the short run, brand SNs do not change the attitudes of those predisposed to joining them.

Brand favorability at Time 2. The second administration of this measure enabled us to test whether treatment-by-selection effects emerge over time. A repeated measures ANOVA using Time (brand favorability at Time 1 versus Time 2) and "liking” status as independent variables revealed only a main effect of the latter $(F(3,2570)=72.37, p<.0005$; Figure 4). Results were the same as at Time 1: relative to those unwilling to "like" the brand, favorability regardless of when it was measured - was significantly higher among those in the opt-in control 
condition $\left(\mathrm{M}_{\text {opt-out }}=4.87, \mathrm{SD}=1.32 ; \mathrm{M}_{\text {opt-in_control }}=5.83, \mathrm{SD}=1.08 ; \mathrm{t}(1390)=12.41, p<\right.$ .0005), the opt-in experimental condition $\left(\mathrm{M}_{\text {opt-in_experimental }}=5.80, \mathrm{SD}=1.03 ; \mathrm{t}(1385)=12.43, p\right.$ $<.0005)$, and those who had already "liked" the brand $\left(\mathrm{M}_{\text {already_ "liked" }}=5.95, \mathrm{SD}=.98\right.$; $\mathrm{t}(323)=$ 5.96, $p<.0005)$. The latter three conditions were not significantly different from each other $(\mathrm{F}(2$, $2306)=.68, p=.51$ ). These results suggest that even in the longer run, brand SNs do not change the attitudes of those predisposed to joining them.

The second administration of brand favorability also enabled us to test whether an effect of “liking” might emerge for opt-inners when paired with advertising. A 4x2 analysis of covariance (controlling for Time 1 brand favorability) revealed a main effect of "liking” status $(\mathrm{F}(3,2565)=9.64, p<.0005)$, consistent with the results reported above. The analysis also revealed a marginally significant main effect of advertising $(\mathrm{F}(1,2565)=3.04, p=.08)$, indicating that brand favorability was higher among participants who had received the advertising message relative to those who had not $\left(\mathrm{M}_{\text {advertisement }}=5.74, \mathrm{SE}=.04 ; \mathrm{M}_{\mathrm{no} \_ \text {advertisement }}=\right.$ $5.63, \mathrm{SE}=.04)$. In addition, the interaction between "liking” status and advertising was marginally significant $(\mathrm{F}(3,2565)=2.15, p=.09)$. Specifically, as is apparent in Figure 4B, the advertising message appears to close the brand favorability gap between those unwilling versus willing to "like" the brand: when advertisements were not shown, there were significant differences in brand favorability as a function of liking status $(\mathrm{F}(3,1272)=11.22, p<.0005)$. Specifically, in the absence of advertising, opt-outers viewed the brand less favorably relative to both opt-inners and those who had already liked the brand $(\mathrm{F}(1,1275)=33.62, p<.0005)$. When advertising was provided, however, there were no significant differences as a function of liking status $(\mathrm{F}(3,1291)=1.51, p=.21)$. Notably, this means that exposing opt-outers to 
advertising caused them to view the brand just as favorably as opt-inners and those who had already liked the brand.

Purchase opportunity. The propensity to buy the lip balm was significantly different as a function of "liking" status $\left(\chi^{2}(3)=62.56, p<.0005\right)$. Purchase rates were significantly lower among opt-outers $(16.4 \%)$ relative to those in the opt-in control condition $\left(38.3 \% ; \chi^{2}(1)=61.26\right.$, $p<.0005)$, the opt-in experimental condition $\left(36.1 \% ; \chi^{2}(1)=50.98, p<.0005\right)$, and those who had already "liked" the brand $\left(31.4 \% ; \chi^{2}(1)=10.00, p=.002\right)$. Purchase rates did not differ among the latter three conditions $\left(\chi^{2}(2)=2.76, p=.25\right)$, again suggesting that "liking” does not causally change consumer behavior. Instead, it appears that being fond of a brand leads consumers to purchase that brand's offerings.

Overall, 32.6\% of participants bought the lip balm during the Time 1 survey. Since the advertising treatment occurred after Time 1 and since participants could only purchase one tube of lip balm, the sample size to test effects of the advertising manipulation on purchasing was restricted to participants who had not already bought the lip balm at the time the email was sent ( $\mathrm{N}=2294)$. Those randomized to receive the advertisement were marginally more likely to buy relative to those who had not received it (Purchase rates: Advertisement $=3.9 \%$, No advertisement $\left.=2.4 \% ; \chi^{2}(1)=4.05, p=.06\right)$. Advertising did not interact with "liking” status ( $p$ $=.62)$.

Bayes factors. For all dependent measures, Bayes factors provide strong evidence for the null. Specifically, the null is 10.45 times more likely for coupon redemption, 24.09 times more likely for brand favorability at Time 1, and 17.65 times more likely for brand favorability at Time 2. 
Consistent with Experiments 2A and 2B, Experiment 2C suggests that being fond of a brand leads consumers to join its brand SN, and not the other way around. Specifically, purchase behavior is the same among consumers who are fond of the brand regardless of when and whether they "like” it on FB. Consistent with Experiment 2B, joining brand SNs changes neither attitudes nor purchasing behavior even when combined with effective advertising.

\section{META-ANALYSIS 2}

As for our experiments designed to test for pure treatment effects, we conducted a metaanalysis of our five experiments (i.e. Experiments 2A-C plus two additional experiments reported in the Web Appendix) that employed an intent-to-“like” procedure, enabling treatmentby-selection effects to be distinguished from selection effects. Consistent with the previous metaanalysis, the effect of the intent-to-“like” manipulation is not positive and if anything, is negative (mean effect size: $\mathrm{d}=-.064, p=.08$ ).

\section{EXPERIMENT 3}

Whereas Experiments 1 and 2 focused on first-order associations between brand SN membership and marketing outcomes, Experiment 3 focuses on second-order associations, examining whether consumers "liking" a brand causes their FB friends to purchase it. We also test how such online endorsement compares to more meaningful endorsements.

Experiment 3 is a field experiment in which we partnered with a new cosmetics brand, Grace Choi. The experiment had two phases. In the first, participants (i.e., referents) were induced to join the brand's FB page and provided the names and email addresses of three friends. The referents were told that each of these friends would be sent a coupon for a free deluxe sample of Grace Choi BB cream. In Phase 2, the friends (i.e., recipients) were emailed the coupon. Each of the referent's three friends was randomized to one of three social endorsement 
conditions. Some recipients were told that their friend liked the brand, others were told that their friend had "liked" the brand (i.e., had joined the brand's FB network), and a third group was simply told their friend had sent them a coupon. We compare coupon redemption rates across conditions.

Procedure

Phase 1. Participants $\left(\mathrm{N}=728 ; 100 \%\right.$ female; $\mathrm{M}_{\text {age }}=34.23$ years, $\mathrm{SD}=4.26 ; N S$ between conditions) from the company’s target market were asked to supply the names and email addresses of three friends and were told that these friends would be sent a coupon for a free deluxe sample from Grace Choi. To discourage referents from entering their own email addresses, they were told (truthfully) that they also would receive a coupon for a deluxe sample. Referent coupons offered a 50\% discount whereas recipient coupons offered a 100\% discount, though this was not made explicit.

Phase 2. After all Phase 1 data had been collected, coupons were distributed to the recipients. In Phase 2, within each triplet of recipients (i.e., the three people that a referent had listed), one friend was randomized to a social control condition, the second to a meaningful social endorsement condition, and the third to a FB social endorsement condition (described below).

Coupon distribution procedure. Recipients were emailed a unique coupon code from the Grace Choi brand, redeemable for a free deluxe sample of BB cream. ${ }^{3}$ The subject line, “Deluxe sample from [referent name]" was the same for all recipients. We manipulated the beginning of the message. In the control condition, the opening line was: "Your friend, [referent name] is sending you a free deluxe sample set of Grace Choi BB cream!” In the meaningful social

\footnotetext{
${ }^{3}$ We pre-tested different coupon amounts. A $\$ 0.50$ sample yielded a $1.9 \%$ redemption rate, a $\$ 0.25$ sample yielded a $0 \%$ redemption rate, and a $\$ 0.00$ (i.e., free) sample yielded a $10.5 \%$ redemption rate.
} 
endorsement condition, the opener was: “your friend, [referent name], likes Grace Choi BB cream. She is sending you a free deluxe sample set of Grace Choi BB cream!” And finally, in the FB social endorsement condition, the opener was: "Your friend, [referent name] liked Grace Choi BB cream on Facebook and joined their Facebook group. She is sending you a free deluxe sample set of Grace Choi BB cream!” (screenshots of the emails are in Web Appendix B).

Using a separate sample of participants (drawn from the same pool), we assessed whether the messages were in fact construed as differing in how meaningful they were - i.e., in the strength of preference that the referent was signaling. Participants $(\mathrm{N}=102)$ ranked the three messages (order of presentation counter-balanced between-subjects) with respect to how indicative they were of the friend's strength of preference for the product. The results confirmed that the meaningful endorsement condition was most commonly ranked as the strongest indicator of the friend's preference (49\% of participants ranked it \#1; compared to 33\%: $\mathrm{z}=3.36, p<$ .0005); the FB endorsement condition was most commonly ranked second (58.8\% of participants ranked it \#2; compared to 33\%: $\mathrm{z}=5.46, p<.0001$ ); and the control endorsement was most commonly ranked third (52.0\% of participants ranked it \#3 compared to 33\%: $\mathrm{z}=4.00, p=$ $.0001)$.

Recipients were given two days to redeem the coupon. We also tracked whether recipients redeemed the coupon multiple times.

Phase 1 Results

Compliance. All referents complied with the request to "like" the brand, as this was a participation requirement. This was important both for internal validity and to avoid deception in Phase 2, in which some recipients were told that their referents had "liked" the brand. All referents supplied three names and email addresses, also a participation requirement. Therefore, 
a total of 2184 names and email addresses were supplied. Of these, $11.6 \%$ were invalid. Thus there were 1930 recipients distributed across the three conditions (control: $\mathrm{n}=638$; meaningful social endorsement: $n=649$; FB social endorsement: $n=643$ ).

Phase 2 Results

Redemption. Redemption rates were low in absolute terms, but high relative to an approximate industry average for email coupons of 2.7\% (CodeBroker 2015). Specifically, coupon redemption rates were 5.2\% in the control condition, 5.9\% in the meaningful social endorsement condition and 3.7\% in the FB social endorsement condition. A logistic regression revealed that coupon redemption was marginally higher in the meaningful social endorsement condition relative to the $\mathrm{FB}$ social endorsement condition $(\beta=.47, \mathrm{SE}=.27, \mathrm{z}=1.77, p=.08)$. Redemption rates were similar between FB social endorsement and control $(\beta=.34, \mathrm{SE}=.27, \mathrm{z}$ $=1.24, N S)$. These results hold in a two-level model with random intercepts controlling for possible referent effects (see the Web Appendix). To our surprise, three respondents ordered twice in the observation span. Consistent with the primary analysis, an exploratory analysis using the total number of orders as the dependent variable revealed that meaningful social endorsement induced more orders relative to FB social endorsement $(\beta=.50, \mathrm{SE}=.26, \mathrm{z}=1.94, p=.05)$. Discussion

Experiment 3 suggests that although social endorsement can increase consumers’ willingness to redeem a coupon and trial a brand, the type of endorsement matters: specifically, the kind of token social endorsement on FB is less effective than social endorsement in which a friend states that she likes - in the offline sense of the word - a brand. 
Taken together, these five experiments make two primary contributions (summarized in Table 1). First, across both attitudinal and behavioral outcomes, and short and longer time spans, the mere act of "liking" a brand has no positive first-order effect on consumer attitudes or purchases; two meta-analyses suggest that if anything, its effect is detrimental. The positive associations between brand SN membership and marketing outcomes are instead a product of selection: being fond of a brand (liking it) increases a person's willingness to join its social network ("liking” it). Specifically, brand attitudes and purchasing are the same among people who are fond of the brand - regardless of when and whether they "like" it on FB. Second, inducing a consumer to "like” a brand may enhance his friends' willingness to try the brand; however, the token nature of the endorsement used on FB is less effective than more meaningful endorsements that are external to FB.

Future research is needed to further unpack the multifaceted role that brand SNs may play in consumer decision-making and in marketing activities. Moreover, such effects might depend on the specific brand in question. Although our results hold across a variety of brands, future research could more comprehensively test whether the marketing impact of brand SNs depends on the nature of the brand (e.g. new vs. established, hedonic vs. utilitarian, etc.).

In our experiments, we assess the impact of inducing consumers to "like" brands on marketing outcomes. Future research could explore whether the manner in which consumers are encouraged to "like" brands impacts the marketing effectiveness of brand SNs. Consistent with research on reactance (Brehm 1966) and crowding out (Deci 1971; Frey and Jegen 2001), these results suggest that simply asking consumers to "like" brands is unlikely to improve attitudes or boost sales. In this vein, future research could examine means of better leveraging a consumer's willingness to comply (i.e., to join a brand's network) into positive marketing outcomes. 
Previous theorizing and research suggest that initial behavior is more likely to lead to subsequent consistent behavior when that initial behavior is costly to the actor (Benabou and Tirole 2006;

Gneezy et al. 2012). The act of liking a brand on FB - requiring mere seconds of attention and, by design, one click of a button - may simply induce too weak a signal of preference for consumers to infer increased liking for the brand. Making joining such communities more difficult - for example, by requiring a series of actions such as a greater number of clicks to gain membership - might increase the impact of liking, akin to research suggesting that effort can lead to greater liking (Aronson and Mills 1959; Norton, Mochon, and Ariely 2012).

In addition, consistent with Manchanda et al.'s (2015) research suggesting that the positive outcomes associated with brand SN membership are driven by those who are active on those communities - and not by those who merely lurk - marketers way wish to encourage, and possibly even incentivize, joiners to post content. Brand SNs may positively impact consumer attitudes and behaviors when members are induced to engage with them, exerting effort after joining. Akin to our intent-to-“like” experimental approach, the effectiveness of such interventions could be assessed using an “intent-to-engage” procedure, whereby brand SN members are first asked whether they are willing to post content, and then randomized to either post or not.

Should marketers invest in garnering “likes”? We find no evidence of direct, first-order benefits from inducing consumers to "like” brands on FB, suggesting that marketers may be prone to over-investing in expanding their social media presence relative to more traditional marketing promotions (e.g., coupons, direct marketing, Ad-Words). Indeed, Experiment 2C shows that simple advertising causes those who decline requests to "like" a brand to view that brand as favorably as those willing to "like.” Moreover, consumers’ willingness to "like” brands 
could give marketers the illusion that their social media efforts are having impact, especially since "number of members" is both a salient and readily-available metric. That said, brand SNs and online brand communities more broadly - are likely a permanent part of the marketing mix, and indeed, some research reveals that certain forms of social media do spur increased sales (Stephen and Galak 2012). However, to the extent that marketers feel compelled to invest in a brand's social network, our results suggest that merely investing in increasing membership - via unsupported "likes” - may not be money well-spent. Instead, marketers might focus on improving the content of the network. For example, revealing the demographic characteristics of brand SN members positively affects brand evaluations and purchase intentions (Naylor, Lamberton, and West 2012). In addition, brands that elicit participation on their FB pages may be positioned to leverage those "likes” into increased revenue.

In sum, it would be wrong to take the present research as evidence of the total ineffectiveness of brand SNs. Instead, FB “liking” may be valuable to marketers when used strategically as a relationship-building, involvement-raising, knowledge-enriching tool. And as a targeting and marketing communications tool, brand SNs allow consumers to self-identify as fans of the brand, potentially helping the brand to build, and engage with, an audience predisposed to be receptive.

So, what are FB “likes” really worth? Our results show that consumers are often willing to "like” brands and so as a means to gain consumer attention - however briefly - "likes” are effective. Turning that attention into improved brand attitudes and increased purchasing by either consumers or their friends, however, appears to require more than just the click of a button. 


\section{REFERENCES}

Aral, Sinan and Dylan Walker (2011), “Creating Social Contagion Through Viral Product Design: A Randomized Trial of Peer Influence in Networks,” Management Science, 57 (9), 1623-1639. and - (2012), "Identifying Influential and Susceptible Members of Social Networks,” Science, 337 (July), 337-341.

Aronson, Elliot and Judson Mills (1959), “The Effects of Severity of Initiation on Liking for a Group,” Journal of Abnormal and Social Psychology, 59 (2), 177-181.

Bapna, Ravi and Akhmed Umyarov (2015), “Do Your Online Friends Make You Pay? A Randomized Field Experiment in an Online Music Social Network,” Management Science, 61 (8), 1902-1920.

Barnes, Nora G., Ava M. Lescault, and Stephanie Wright (2013), “2013 Fortune 500 are bullish on social media: Big companies get excited about Google+, Instagram, Foursquare and Pinterest,” (accessed February 8, 2016), [available at http://www.umassd.edu/cmr/socialmediaresearch/2013fortune500/]

Benabou, Roland and Jean Tirole (2006), “Incentives and Prosocial Behavior,” American Economic Review, 96 (5), 1652-1678.

Brehm, Jack W. (1966), A Theory of Psychological Reactance. New York: Academic Press. CodeBroker (2015), “Realizing Significant ROI using Digital Coupon Mobile Engagement,” (accessed February 8, 2016), [available at http://pointofsale.com/Success-stories/StudyShows-ROI-for-Mobile-Coupon-Redemption.html] 
Creamer, Matthew (2012), “Study: Only 1\% of Facebook 'Fans' Engage With Brands,” Ad Age Digital, (accessed February 8, 2016), [available at http://adage.com/article/digital/study1-facebook-fans-engage-brands/232351/]

Deci, Edward L. (1971), “Effects of Externally Mediated Rewards on Intrinsic Motivation,” Journal of Personality and Social Psychology, 18 (1), 105-115. eMarketer (2012), “What Are Marketers Spending on Social Media?” (accessed February 8, 2016), [available at http://www.emarketer.com/Article/What-Marketers-Spending-onSocial-Media/1009201]

Frey, Bruno S. and Reto Jegen (2001), “Motivation Crowding Theory,” Journal of Economic Surveys, 15 (5), 589-611.

Gneezy, Ayelet, Alex Imas, Amber Brown, Leif D. Nelson, and Michael I. Norton (2012), “Paying to be Nice: Costly Prosocial Behavior and Consistency,” Management Science, 58 (1), 179-187.

Greene, William H. (2012), Econometric Analysis. 7th International Ed., Pearson, Chapter 6. Kass, Robert E. and Adrian E. Raftery (1995), “Bayes Factors,” Journal of the American Statistical Association, 90 (430), 773-795.

Kristofferson, Kirk, Katherine White, and John Peloza (2014), “The Nature of Slacktivism: How the Social Observability of an Initial Act of Token Support Affects Subsequent Prosocial Action,” Journal of Consumer Research, 40 (6), 1149-1166.

Lechner, Michael (2011), “The Estimation of Causal Effects by Difference-in-Difference Methods,” Foundations and Trends in Microeconomics, 4 (3), 165-224. 
Lipsman, Andrew, Graham Mudd, Mike Rich, and Sean Bruich (2012), “The Power of Like: How Brands Reach (and Influence) Fans Through Social Media Marketing,” Journal of Advertising Research, 52 (1), 40-52.

McPherson, Miller, Lynn Smith-Lovin, and James M. Cook (2001), “Birds of a Feather: Homophily in Social Networks,” Annual Review of Sociology, 27 (2001), 415-444.

Manchanda, Puneet, Grant Packard, and Adithya Pattabhiramaiah (2015), “Social Dollars: The Economic Impact of Customer Participation in a Firm-sponsored Online Community,” Marketing Science, 34 (3), 367-387.

Naylor, Rebecca W., Cait P. Lamberton, and Patricia M. West (2012), “Beyond the "Like” Button: The Impact of Mere Virtual Presence on Brand Evaluations and Purchase Intentions in Social Media Settings,” Journal of Marketing, 76 (6), 105-120.

Norton, Michael I., Daniel Mochon, and Dan Ariely (2012), “The IKEA Effect: When Labor Leads to Love,” Journal of Consumer Psychology, 22 (3), 453-460.

Oestreicher-Singer, Gal and Lior Zalmanson (2010), "Paying for Content or Paying for Community? The Effect of Social Computing Platforms on Willingness to Pay in Content Websites,” working paper, Tel-Aviv University.

Stephen, Andrew T. and Jeff Galak (2012), "The Effects of Traditional and Social Earned Media on Sales: A Study of a Microlending Marketplace,” Journal of Marketing Research, 49 (5), 624-639.

Vranica, Suzanne and Shayndi Raice (2012), “The Big Doubt Over Facebook,” The Wall Street Journal, (accessed February 8, 2016), [available at http://online.wsj.com/article/SB10001424052702304868004577378122958515302.html] 
TABLE 1

SUMMARY OF EXPERIMENTS AND FINDINGS

\begin{tabular}{|c|c|c|c|c|c|c|c|}
\hline & $\begin{array}{c}\text { Experiment } 1 \\
(N=767)\end{array}$ & Meta-Analysis 1 & $\begin{array}{c}\text { Experiment } 2 A \\
(N=1343)\end{array}$ & $\begin{array}{c}\text { Experiment 2B } \\
(N=940)\end{array}$ & $\begin{array}{c}\text { Experiment 2C } \\
(N=4841)\end{array}$ & Meta-Analysis 2 & $\begin{array}{c}\text { Experiment } 3 \\
(N=728)\end{array}$ \\
\hline $\begin{array}{l}\text { Research } \\
\text { Question }\end{array}$ & \multicolumn{2}{|c|}{$\begin{array}{l}\text { Does inducing consumers to } \\
\text { "like" a brand cause them to } \\
\text { view it more favorably? }\end{array}$} & \multicolumn{4}{|c|}{$\begin{array}{c}\text { Does inducing consumers who have a pre-existing fondness for a } \\
\text { brand cause them to view it even more favorably? }\end{array}$} & $\begin{array}{l}\text { Does "liking" a brand cause a } \\
\text { person's friends to buy it? }\end{array}$ \\
\hline $\begin{array}{l}\text { Primary } \\
\text { outcome } \\
\text { measure }\end{array}$ & \multicolumn{2}{|c|}{ Brand favorability } & \multicolumn{2}{|c|}{ Brand favorability } & Purchasing & $\begin{array}{l}\text { Brand } \\
\text { favorability }\end{array}$ & Purchasing \\
\hline $\begin{array}{l}\text { Primary } \\
\text { Conclusion }\end{array}$ & \multicolumn{2}{|c|}{$\begin{array}{l}\text { Inducing consumers to "like" a } \\
\text { brand does not impact brand } \\
\text { favorability. }\end{array}$} & \multicolumn{4}{|c|}{$\begin{array}{l}\text { Inducing consumers possessing a pre-existing fondness toward a } \\
\text { brand to "like" that brand impacts neither brand favorability nor } \\
\text { purchasing behavior. Brand favorability and purchasing is the same } \\
\text { among people who are fond of a brand - regardless of when and } \\
\text { whether they "like" it. }\end{array}$} & $\begin{array}{l}\text { Seeing that a friend has } \\
\text { "liked" a brand makes a } \\
\text { person less likely to buy it } \\
\text { relative to more meaningful } \\
\text { social endorsement. }\end{array}$ \\
\hline
\end{tabular}


FIGURE 1

LIKING INDUCTION (AND CONTROL INDUCTION) FOR EXPERIMENT 1

\section{Experimental:}

Please click on the 'like' button below for the brand: Coca-Cola

Note: clicking 'like' will automatically post this to your Facebook account.

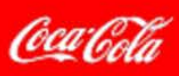

ff Like $\{96 \mathrm{M}$

\section{Control:}

Please check the box below to indicate if you like the brand: Coca-Cola

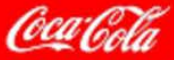

$\square$ Like 
FIGURE 2

BRAND FAVORABILITY BY CONDITION (EXPERIMENT 2A)

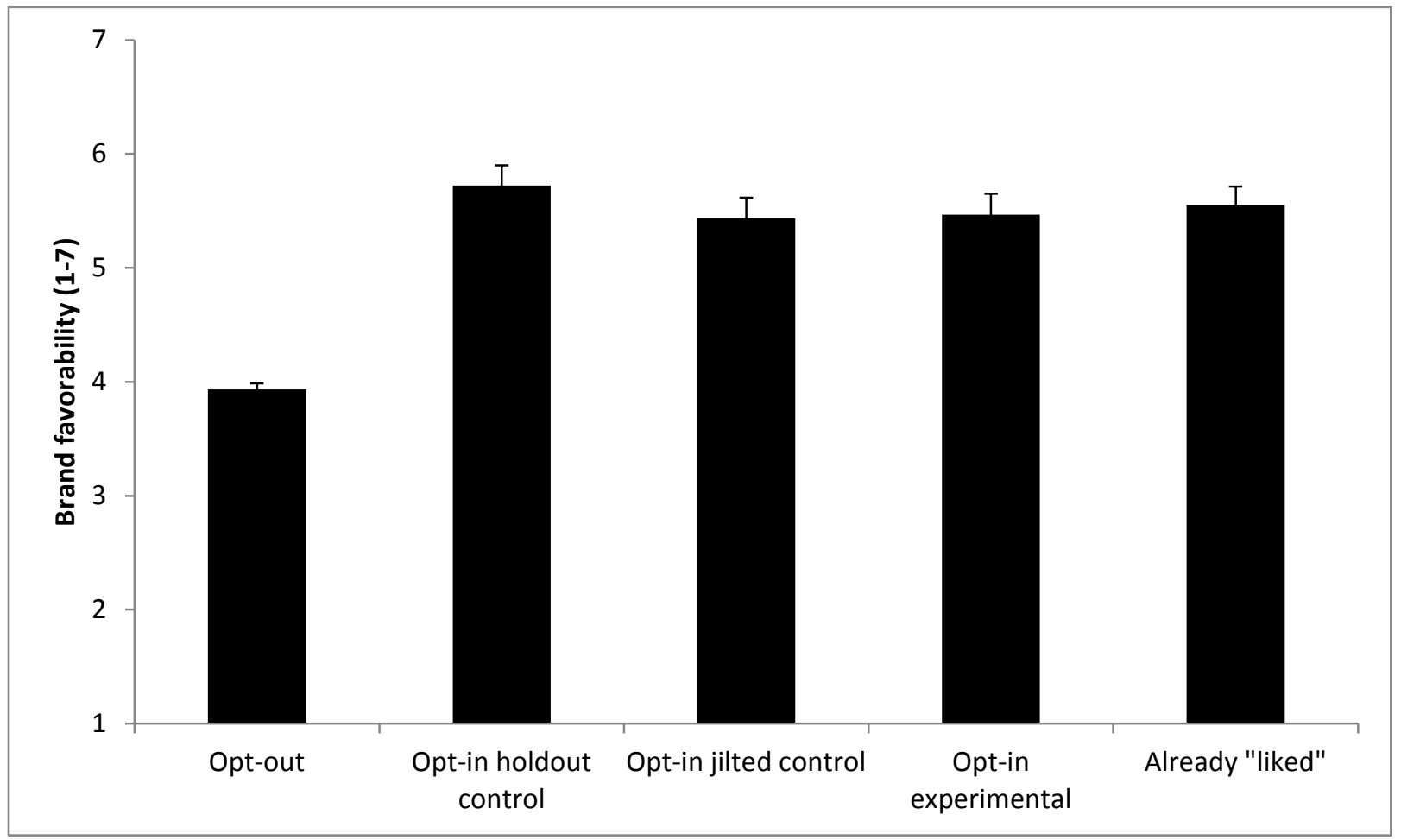


FIGURE 3

BRAND FAVORABILITY BY CONDITION (EXPERIMENT 2B)

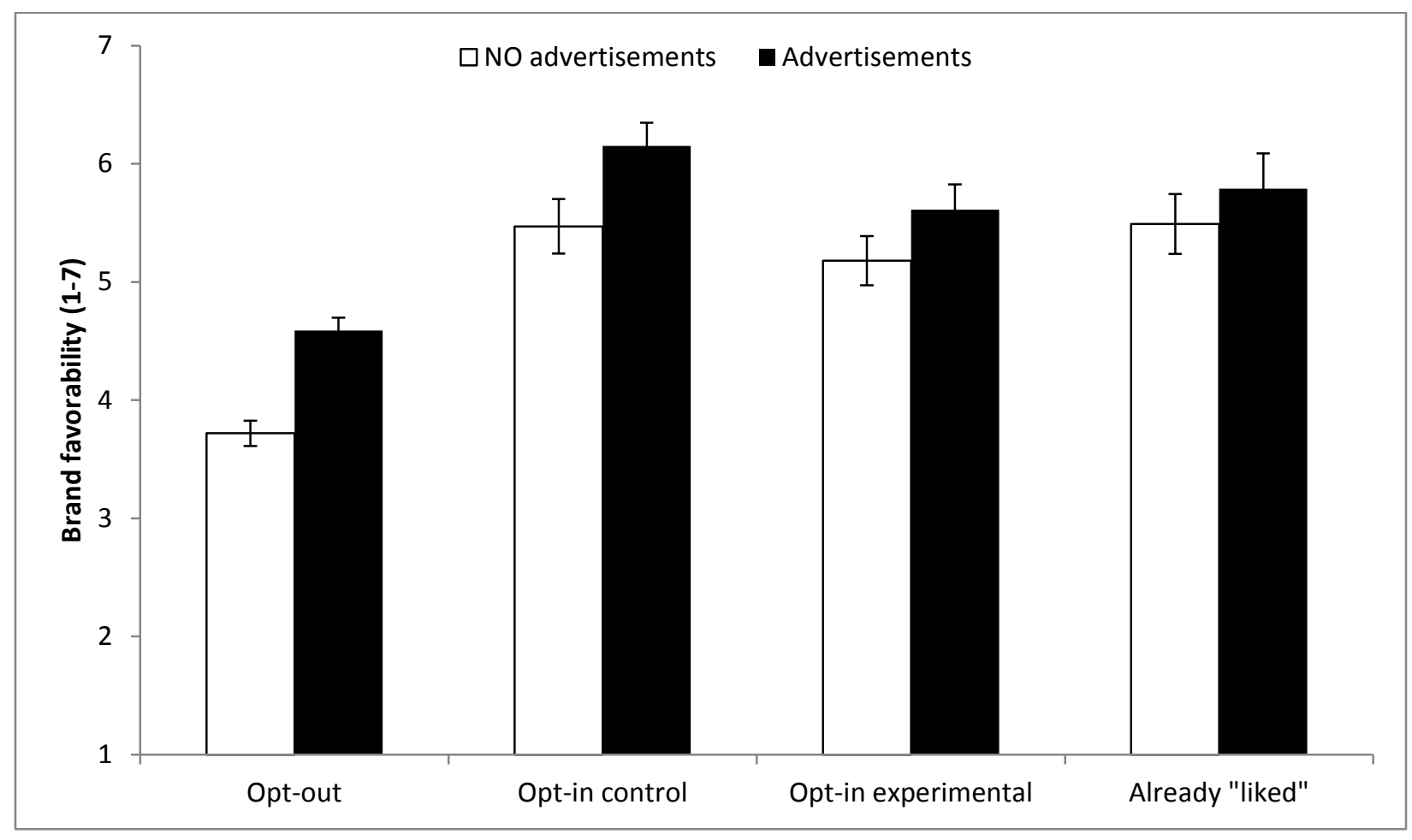


FIGURE 4A

BRAND FAVORABILITY AT TIME 1 AND TIME 2 BY “LIKING” STATUS

(EXPERIMENT 2C)

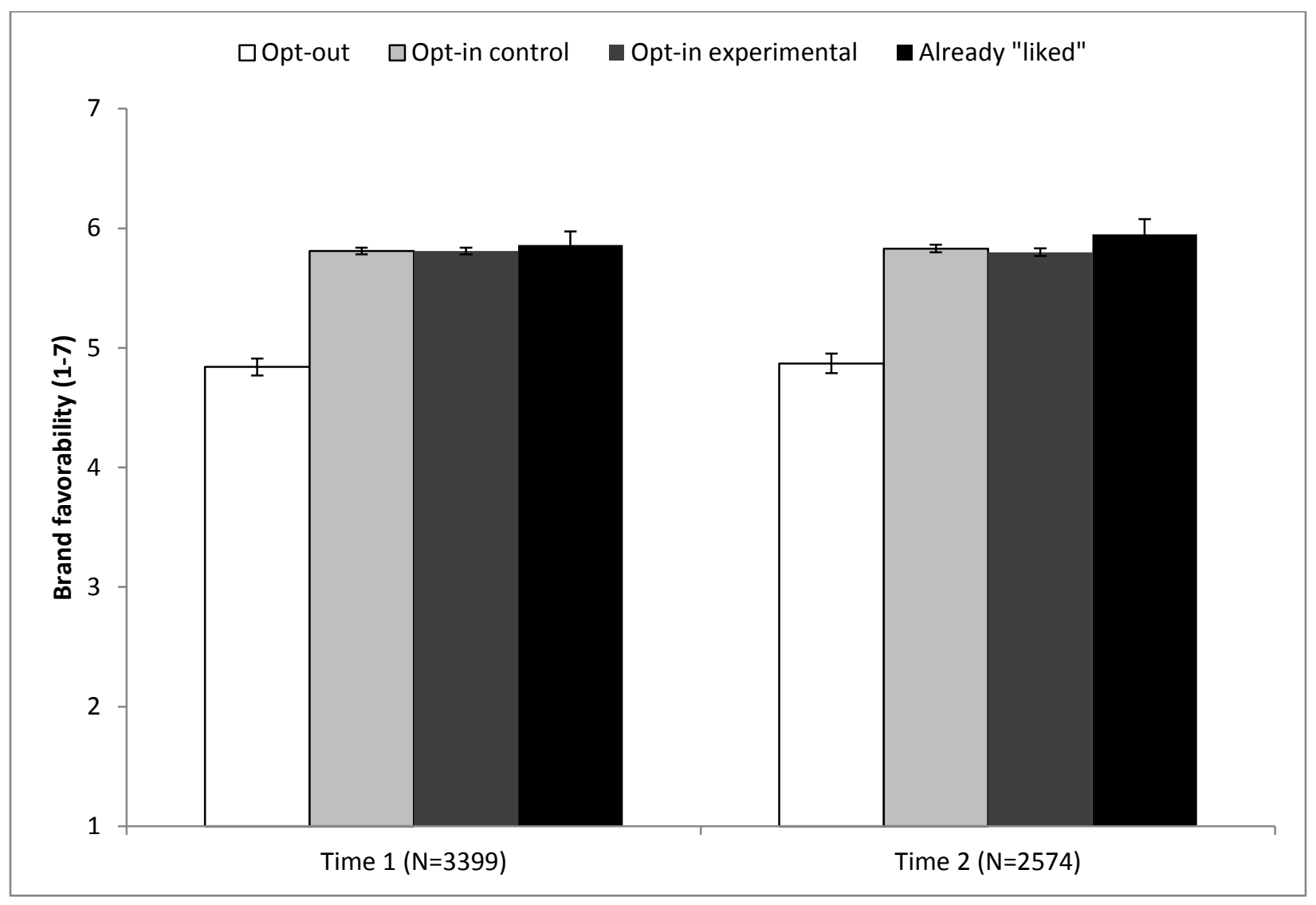


FIGURE 4B

BRAND FAVORABILITY BY “LIKING” STATUS AND ADVERTISING MANIPULATION (EXPERIMENT 2C)

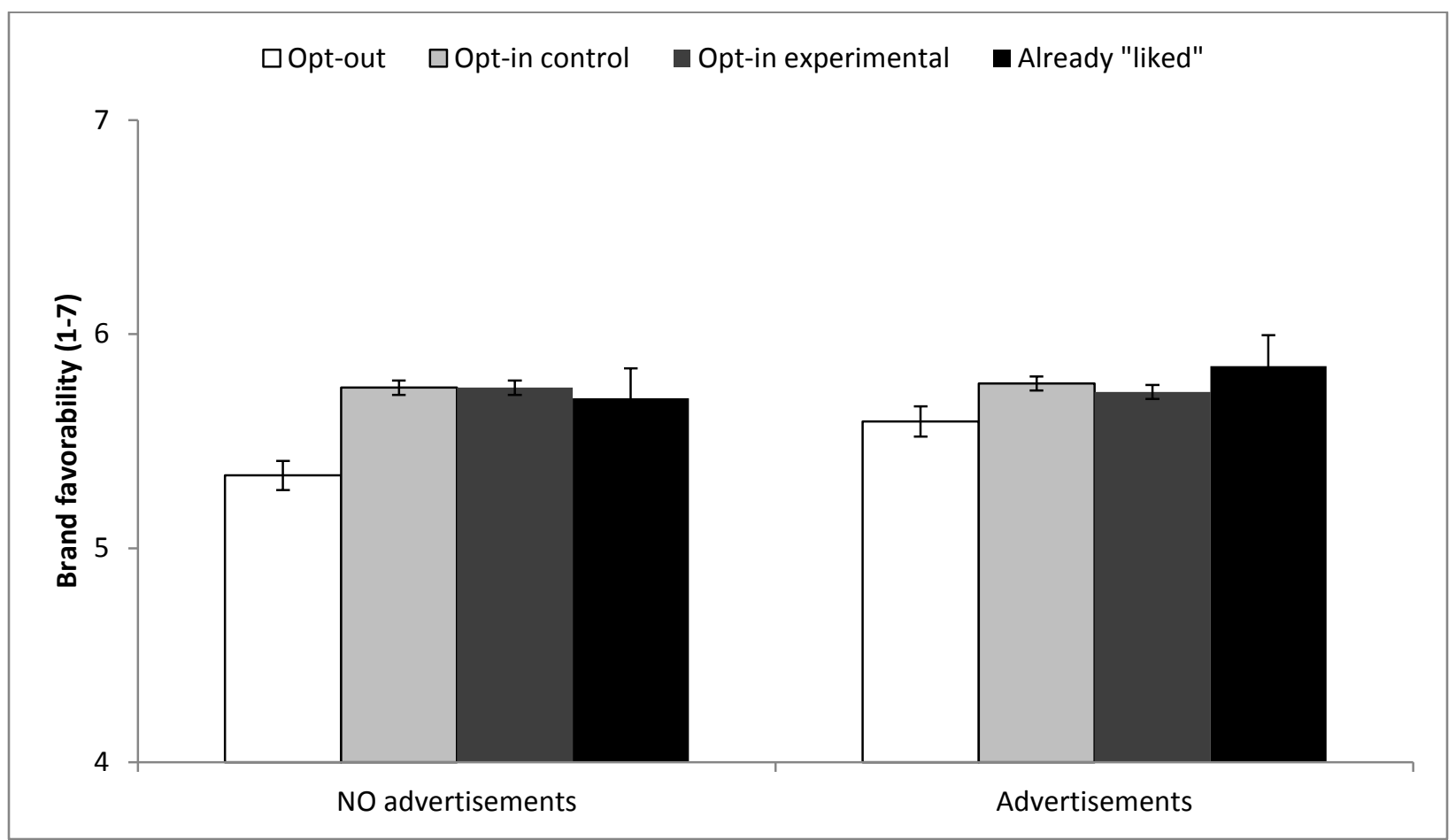

